\title{
Comparison of ORNL Low Cost Carbon Fiber with Commercially Available Industrial Grade Carbon Fiber in Pultrusion Samples
}

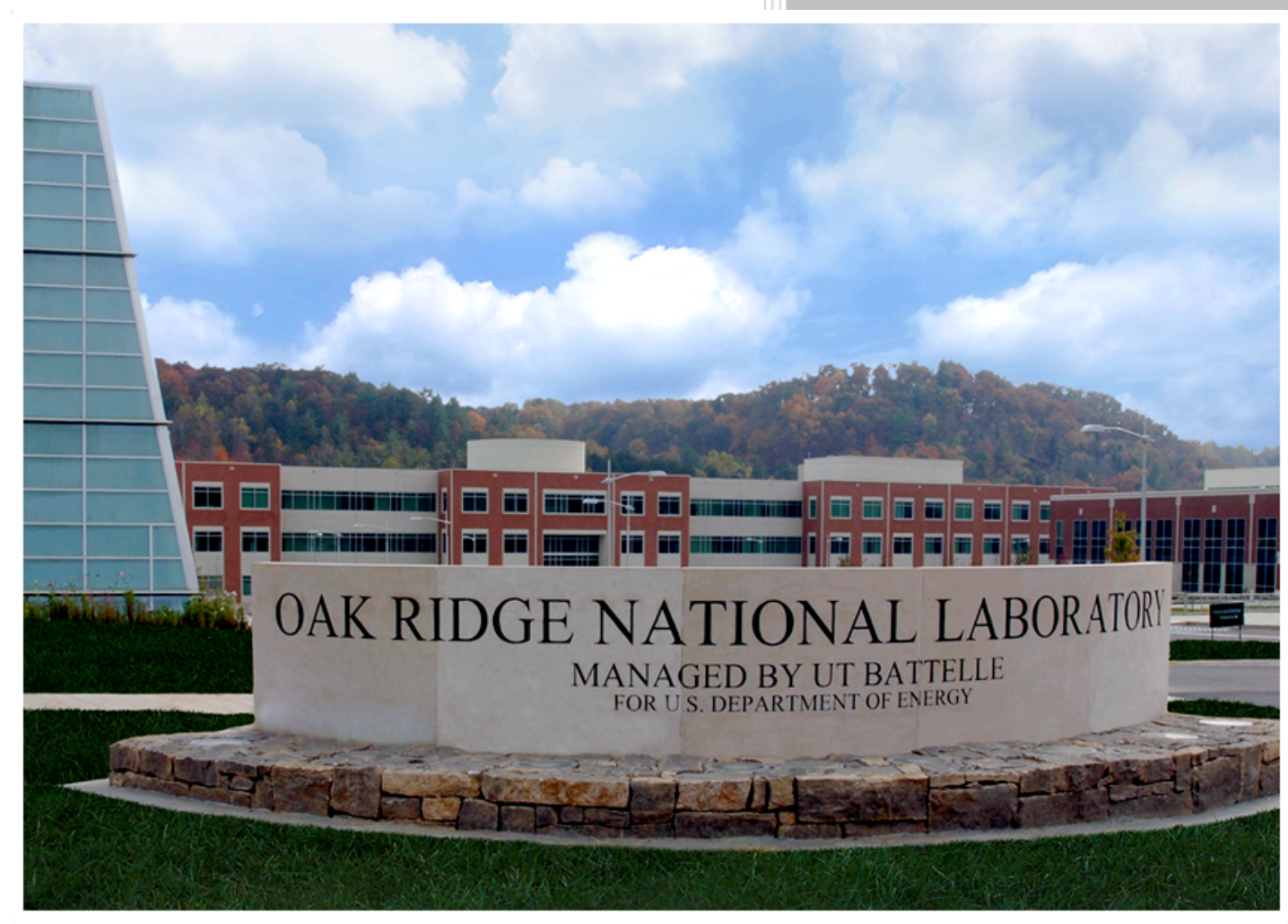

\section{Approved for Public Release} Distribution is Unlimited.

R. E. Norris

February 22, 2016 


\title{
DOCUMENT AVAILABILITY
}

Reports produced after January 1, 1996, are generally available free via US Department of Energy (DOE) SciTech Connect.

Website http://www.osti.gov/scitech/

Reports produced before January 1, 1996, may be purchased by members of the public from the following source:

\author{
National Technical Information Service \\ 5285 Port Royal Road \\ Springfield, VA 22161 \\ Telephone 703-605-6000 (1-800-553-6847) \\ TDD 703-487-4639 \\ Fax 703-605-6900 \\ E-mail info@ntis.gov \\ Website http://www.ntis.gov/help/ordermethods.aspx
}

Reports are available to DOE employees, DOE contractors, Energy Technology Data Exchange representatives, and International Nuclear Information System representatives from the following source:

Office of Scientific and Technical Information

PO Box 62

Oak Ridge, TN 37831

Telephone 865-576-8401

Fax 865-576-5728

E-mail reports@osti.gov

Website http://www.osti.gov/contact.html

This report was prepared as an account of work sponsored by an agency of the United States Government. Neither the United States Government nor any agency thereof, nor any of their employees, makes any warranty, express or implied, or assumes any legal liability or responsibility for the accuracy, completeness, or usefulness of any information, apparatus, product, or process disclosed, or represents that its use would not infringe privately owned rights. Reference herein to any specific commercial product, process, or service by trade name, trademark, manufacturer, or otherwise, does not necessarily constitute or imply its endorsement, recommendation, or favoring by the United States Government or any agency thereof. The views and opinions of authors expressed herein do not necessarily state or reflect those of the United States Government or any agency thereof. 
ORNL/TM-2016/86

MDF-UP-2012-005

Materials Science and Technology Division

Advanced Manufacturing Office

\section{Comparison of ORNL Low Cost Carbon Fiber with Commercially Available Industrial Grade Carbon Fiber in Pultrusion Samples}

Authors

R. E. Norris, PI

Jeff McCay

Connie Jackson

Date Published:

February 22, 2016

Prepared by

OAK RIDGE NATIONAL LABORATORY

Oak Ridge, Tennessee 37831-6283

managed by

UT-BATTELLE, LLC

for the

US DEPARTMENT OF ENERGY

under contract DE-AC05-00OR22725

Approved For Public Release 



\section{CONTENTS}

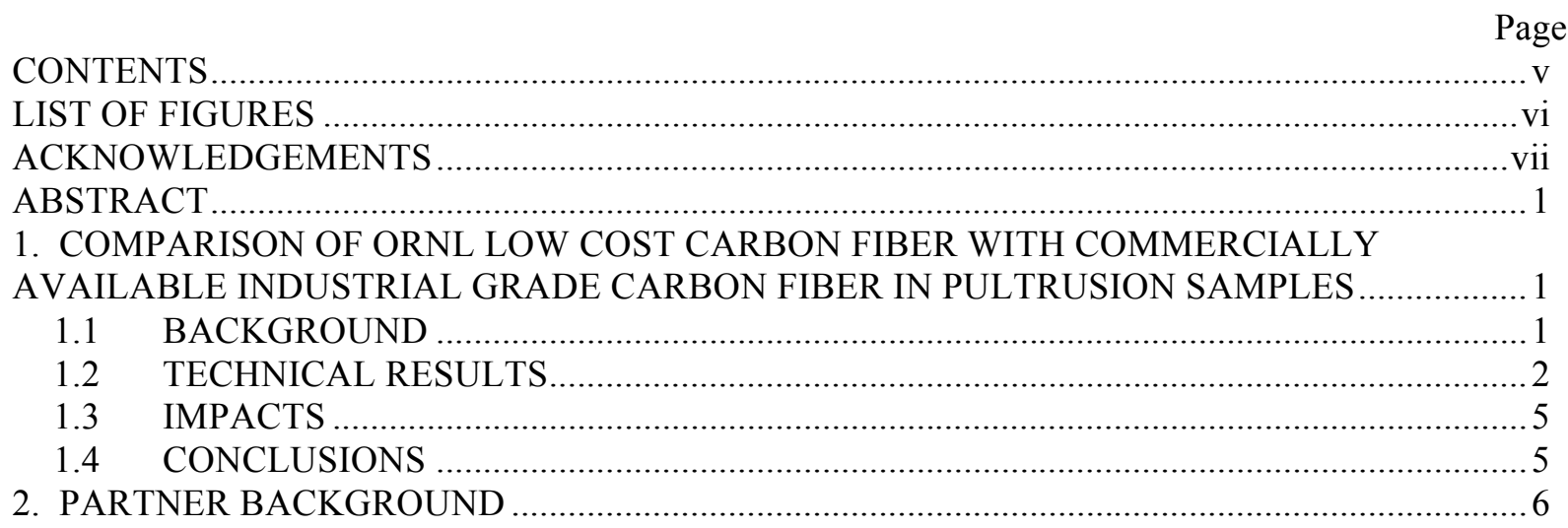




\section{LIST OF FIGURES}

Fig. 1. Depiction of Heil dry bulk tanker subsystem on the left and pultruded composite structural member modified in CAG/Heil collaboration.

Fig. 2. Example problems with getting the Kaltex-based large tow through the pultrusion process. 3

Fig. 3. Best pultruded composite section produced from Kaltex-based large-tow fiber. 


\section{ACKNOWLEDGEMENTS}

This Technical Collaboration project, MDF-UP-2012-5, was conducted within the Oak Ridge National Laboratory (ORNL) Manufacturing Demonstration Facility (MDF) sponsored by the US Department of Energy Advanced Manufacturing Office (CPS Agreement Number 24761).

Opportunities for MDF technical collaborations are listed in the announcement "Manufacturing Demonstration Facility Technology Collaborations for US Manufacturers in Advanced Manufacturing and Materials Technologies" posted at http://web.ornl.gov/sci/manufacturing/docs/FBO-ORNL-MDF-2013-2.pdf. The goal of technical collaborations is to engage industry partners to participate in short-term, collaborative projects within the Manufacturing Demonstration Facility (MDF) to assess applicability and of new energy efficient manufacturing technologies. Research sponsored by the U.S. Department of Energy, Office of Energy Efficiency and Renewable Energy, Advanced Manufacturing Office, under contract DE-AC0500OR22725 with UT-Battelle, LLC. Carbon fiber was provided by the ORNL Carbon Fiber Technology Facility (CFTF) jointly funded by the Advanced Manufacturing Office and the Vehicle Technology Program. 



\begin{abstract}
Composite Applications Group LLC in collaboration with Heil Trailer International partnered in a project to design and develop solutions for light weighting of aluminum dry bulk tank trailers. The project approach was to utilize pultruded composite sections in place of aluminum components to reduce weight thereby saving energy through more efficient transport. Low cost carbon fiber was evaluated as a potential cost saving option that could enhance weight savings at reduced cost versus current commercial material.
\end{abstract}

\title{
1. COMPARISON OF ORNL LOW COST CARBON FIBER WITH COMMERCIALLY AVAILABLE INDUSTRIAL GRADE CARBON FIBER IN PULTRUSION SAMPLES
}

This phase 1 technical collaboration project (MDF-UP-2012-5) was begun on December, 2012 and was completed on December 2016. The collaboration partner, Composites Application Group or $\mathrm{CAG}$, is a small business. Potential low cost carbon fiber forms were evaluated and feedback provided to the Oak Ridge National Laboratory (ORNL) Carbon Fiber Technology Facility (CFTF) on desirable characteristics to achieve in future product forms.

\subsection{BACKGROUND}

Composite Applications Group LLC, an East Tennessee small business, in collaboration with Heil Trailer international is working to engineer and develop composite intensive design options for converting key components in Heil's dry bulk tanker line. The goal of this larger effort is to incorporate carbon fiber and other composite solutions to the existing tank trailer to provide significant weight savings to increase payload capacity without exceeding Department Of Transportation weight limit regulations. The majority of dry bulk tankers today are not fully utilized because weight limits are exceeded before the tank is completely filled. This limitation creates the need for multiple loads being necessary to fulfill the haul need. The objective of the CAG/Heil partnership was to identify light weighting solutions by incorporating composite materials while maintaining the economy of the tanker construction to insure the container cost does not exceed the cost that the customer is willing to pay. The ability to incorporate low cost carbon fiber into some of the proposed solutions would potentially provide weight savings that the Heil client is seeking for operational efficiencies without resulting in a discouraging construction cost penalty.

At the time of project initiation, the $\mathrm{CAG} / \mathrm{Heil}$ team had just completed a major conversion of an extruded aluminum support member shown in Figure 1 by converting it into a pultruded carbon fiber composite support member. The baseline redesign incorporates unidirectional industrial grade carbon fiber (24K tow) with a non woven fiberglass mat pultruded to shape. This design has been modeled and a complete finite element analysis (FEA) has been performed on this proposed design. The proposed design has passed all of the customer load cases with a $3 \mathrm{X}$ safety factor achieved. The team had released pultrusion tooling built specifically to produce a 4.5" X .193" X 50' test component. The manufacturing approach utilized to produce these test components was employed as baseline to validate the FEA modeling.

The objective of this Technology Collaboration project was to evaluate potential incorporation of a comparable low cost carbon fiber from the ORNL Manufacturing Demonstration Facility 
(MDF)/Carbon Fiber Technology Facility (CFTF) for consideration as a potential lower cost future option and to provide feedback to the development of lower cost carbon fiber product forms.
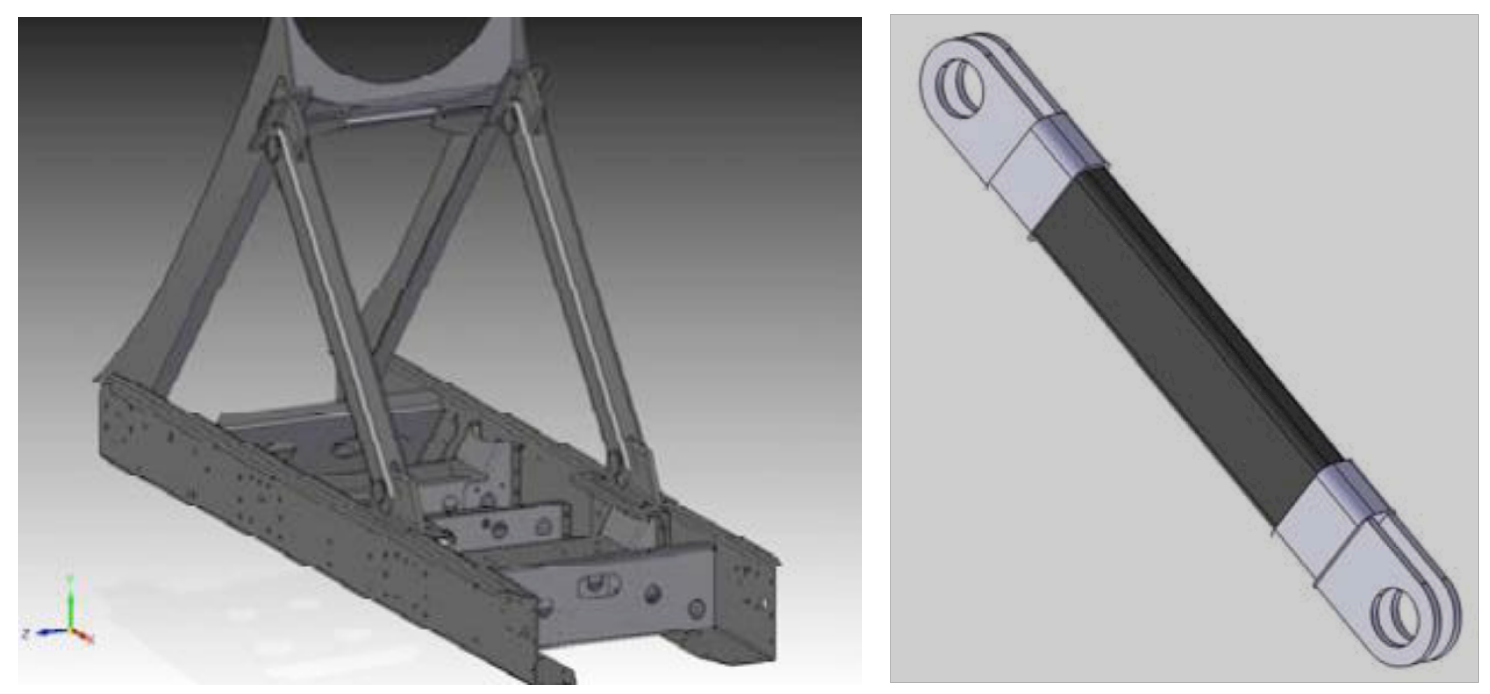

Fig. 1. Depiction of Heil dry bulk tanker subsystem on the left and pultruded composite structural member modified in CAG/Heil collaboration.

Project plans were for ORNL to provide low cost carbon fiber surface treated and sized for use with an epoxy resin system. (In this context, size or sizing refers to a coating applied to carbon fiber to protect the fiber in subsequent operations. This polymeric coating also preserves effectiveness of the surface treatment and facilitates compatibility of the composite matrix system with the treated fiber surface.) With this material, the team planned pultruding a similar test section utilizing low cost carbon fiber at CAG team member Diversified Structural Composites (DSC), a custom pultruder who has substantial experience in working with carbon fiber. This trial would validate the pultrusion quality of the material compared to the industrial grade sample. If an appropriate sample quantity could be produced within the limited resources of this project, it would then be evaluated under the same test criteria as the industrial grade pultrusion sample. The result would provide a good comparison of a carbon fiber design utilizing currently available industrial grade material along side of the same design incorporating the low cost material. These results would highlight how this material performs compared to currently commercialized material.

\subsection{TECHNICAL RESULTS}

ORNL and the CAG/DSC team conducted several teleconferences to explore preferred formatting of carbon fiber material for the pultrusion trials to be conducted at DSC. In evaluating formats, the team considered how to accomplish the most direct comparison of fiber/composite performance with the baseline materials and processes, while maintaining desirable cost benefits from products producible at CFTF. Although initial thoughts were to employ carbon fiber based on precursor supplied by ORNL partner FISIPE, the team decided it was best to transfer focus to fiber provided by Kaltex due to projected cost and availability advantages.

A major difference between the Kaltex and baseline materials was that the Kaltex precursor material was only available in tow filament counts of approximately 400K-600K (400,000-600,000 individual filaments in a single tow) during the span of this project, while the baseline carbon fibers 
typically pultruded by DSC would normally be in tow filament counts of $12 \mathrm{~K}-50 \mathrm{~K}$. Making substantial changes to the Kaltex carbon fiber format such as splitting the tow to a smaller form was well outside the scope of this project, although there was some ORNL/Kaltex collaborative work going on during this time period to do this and the team was apprised of continuing advances in this progression. Acknowledging the challenges, the project team agreed to work towards evaluating the possibility of utilizing a variant of the Kaltex-based product form and project planning discussions focused on how best to size (type and level of coating) and ship the product from CFTF and how best to set up, handle, and process at DSC.

During the course of this project, ORNL/CFTF supplied a couple of fiber products to DSC for evaluation and the planned larger-scale pultrusion trial. The first sample was produced using a fiber sizing ORNL had been using for a wide variety of applications. Based on experience with this form, the second variant was produced with a proprietary sizing provided specifically for this project by Toho Tenax America, the carbon fiber manufacturer whose fiber was utilized in the baseline redesign and is the current owner of DSC. DSC provided qualitative feedback on the product forms, made changes to their pultrusion process setup and operations, and attempted to complete pultrusion trials with the product forms. Unfortunately, even with utilization of the Toho sizing during fiber manufacturing at ORNL and changes made by DSC independently and through consultation with ORNL, the pultrusion trials were not fully successful. Figure 2 shows fiber going through the DSC wet-out system and into the pultrusion die. It is clear that the non-uniform tow tension, fiber entanglement in general, and large numbers of fiber breaks are combining to "clog' the process and inhibit production of a quality pultruded section for testing. Figure 3 shows the best pultruded composite section produced during trials at DSC. Only a few specimens were able to be tested from this section and the poor quality of the test coupons made data deemed to be unreliable for comparison purposes. As originally proposed, CAG did provide a proprietary report summarizing test results from testing their baseline commercial materials and processes, but it was clear that results provided from testing the low cost carbon fiber as part of this project are not suitable for comparison.

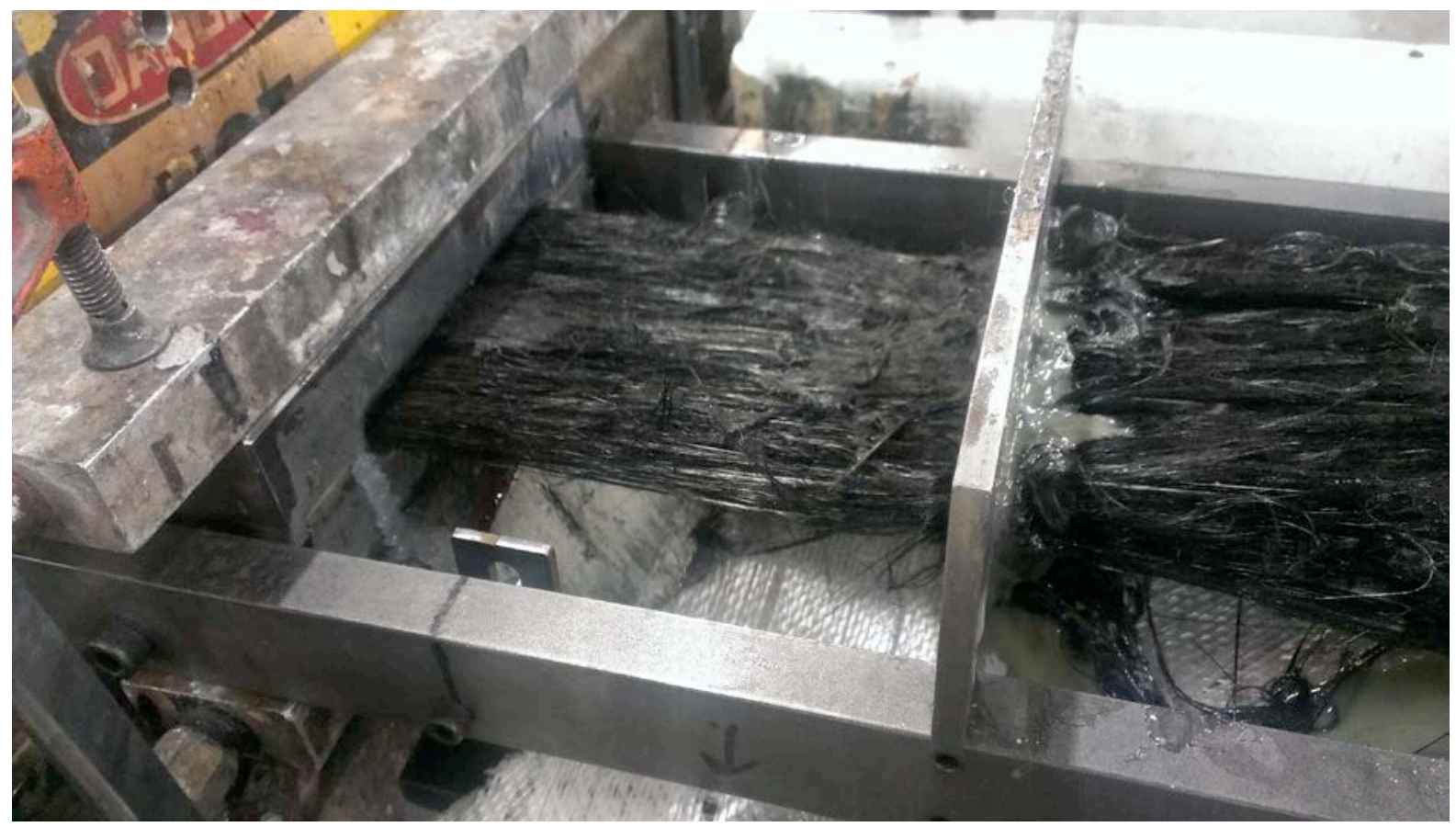

Fig. 2. Example problems with getting the Kaltex-based large tow through the pultrusion process. 


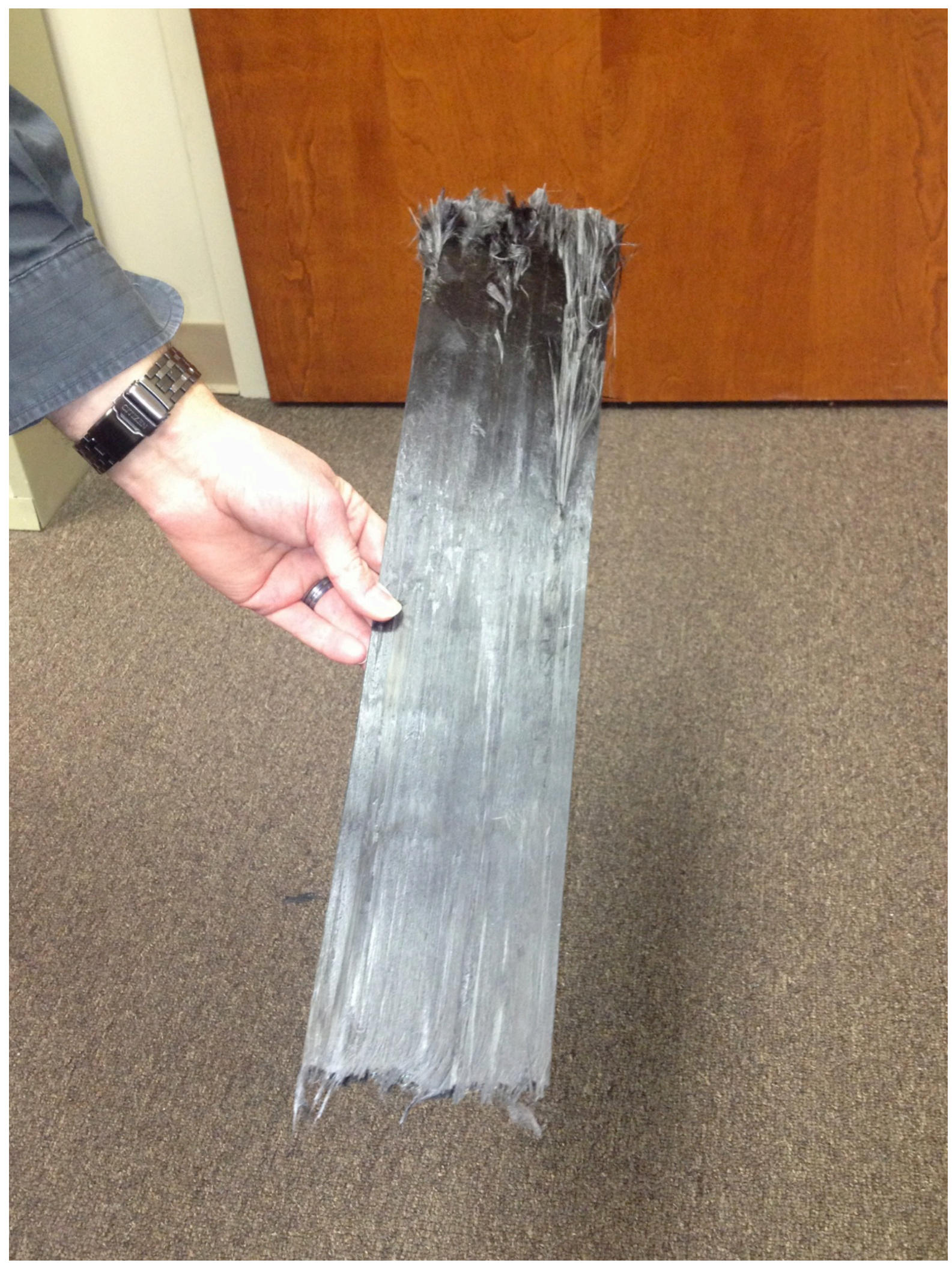

Fig. 3. Best pultruded composite section produced from Kaltex-based large-tow fiber. 


\subsection{IMPACTS}

The conversion of the aluminum strut on the dry bulk tanker to a carbon fiber composite component was projected to reduce trailer weight by $60 \mathrm{lbs}$. This weight savings would in some cases allow increased capacity of the trailer resulting in a reduction in the number of trips while in other cases the benefit is lower fuel usage during the trip. In both cases, the fuel usage per pound of payload is enhanced. Conversion to the carbon fiber composite strut results in some cost penalty for the raw materials due to the likely higher cost of the carbon fiber versus structural aluminum. Potentially offsetting some of the costs of the construction materials is that use of composites could take advantage of lower cost tooling, depending on manufacturing assumptions. Regardless, if adequate performance can be achieved with the lower cost carbon fiber, there is highly likelihood that the lower cost carbon fiber would make the conversion from aluminum more attractive than for the baseline industrial carbon fiber baseline.

Unfortunately, an acceptable low cost carbon fiber form from ORNL was not available in adequate quantities during the span of project activities. The CAG/Heil team needed to make goforward decisions on transition options based on highly certain product performance and pricing while at the same time both factors are yet to be determined for the Kaltex-based low cost carbon fiber. Therefore the decision was made to terminate this work rather to continue to wait for ongoing improvements in this progression from CFTF. However, observations and experience from this project have been valuable feedback in project planning and setting product for targets for CFTF.

\subsection{CONCLUSIONS}

The primary objectives of this project were to provide information to the $\mathrm{CAG} /$ Heil development team and other potential end users on status of CFTF low cost carbon fiber materials with respect to processing and performance characteristics, how these characteristics would likely impact life cycle economic impact in actual real world application, and provide useful feedback to ORNL and DOE for project planning and setting product format and performance targets. Although the team did not achieve adequate performance in pultrusion trials to justify short-term utilization in the application of interest to the $\mathrm{CAG} / \mathrm{Heil}$ team in their introduction of the targeted structural members for dry bulk trailer, the project did provide useful feedback to ORNL on future product needs. In spite of current limitations, the industrial partners maintain interest in the development of low cost carbon fiber forms from ORNL and the overall low cost carbon fiber initiative for future applications. 


\section{PARTNER BACKGROUND}

Composite Applications Group (CAG) is a small business devoted to providing partnering organizations with a source of qualified business leads from companies that have committed, at an executive level, to use composites in their industrial applications. CAG is a resource for member companies turning potential customers to help determine the best materials and processes for their parts. CAG specializes in part, process and prototype design and will use that general knowledge along with the knowledge and direction of our members to provide best practices for individual applications. 